\title{
The rocky roots of the acetyl-CoA pathway
}

\author{
Michael J. Russell ${ }^{1}$ and William Martin ${ }^{2}$ \\ ${ }^{1}$ Scottish Universities Environmental Research Centre, East Kilbride, Glasgow G75 00F, UK \\ ${ }^{2}$ Institute of Botany, University of Düsseldorf, 40225 Düsseldorf, Germany
}

\begin{abstract}
Geologists have suggested that life might have emerged at hydrothermal vents, chemists have shown that metal sulphides such as FeS and NiS can catalyse biochemical reactions in the absence of proteins, and biologists have suggested that the acetyl-coenzyme-A (CoA) pathway of $\mathrm{CO}_{2}$ fixation might be very ancient. New findings from the enzymes at the heart of the acetyl-CoA pathway, carbon monoxide dehydrogenase (CODH) and acetyl-CoA synthase (ACS), indicate that metals and metal sulphides do the biochemical work of $\mathrm{CO}_{2}$ fixation. Here we propose that biochemistry got started when the two volatiles that were thermodynamically furthest from equilibrium on the early Earth - namely, marine $\mathrm{CO}_{2}$ from volcanoes and hydrothermal $\mathrm{H}_{2}$ - met at a hydrothermal vent rich in metal sulphides. In this 'hydrothermal reactor' hypothesis, a primitive, inorganically catalysed analogue of the exergonic acetyl-CoA pathway, using $\mathrm{H}_{2}$ as the initial electron donor and $\mathrm{CO}_{2}$ as the initial acceptor, was instrumental in the synthesis of organic precursors to fuel primordial biochemical reactions. We suggest that primordial biochemistry was housed in an acetate-producing hydrothermal reactor that retained reduced carbon compounds produced within its naturally forming inorganic confines.
\end{abstract}

"Life, geologically speaking, consists of the interference with secondary lithosphere-atmosphere reactions so as to produce a small but ever-renewed stock of organic molecules" J.D. Bernal [1].

Current views on the beginnings of life tend to fall into two well-entrenched camps: organic soup and surface metabolism. Proponents of the organic soup theory suggest that life originated through the organization of organic molecules that were produced in the atmosphere by a Miller-Urey type of reaction or were delivered to Earth from space [2]. As the source of free energy to make, for example, ATP or any other energy currency, simple fermentations (oxidations of pre-existing reduced organic compounds) have been suggested [3]. Proponents of the surface metabolism theory, by contrast, contend that metabolism arose autotrophically (starting from $\mathrm{CO}_{2}$ alone) on the surface of the mineral pyrite $\left(\mathrm{FeS}_{2}\right)$. As the source of free energy, the oxidative formation of pyrite from iron monosulphide $(\mathrm{FeS})$ and hydrogen sulphide $\left(\mathrm{H}_{2} \mathrm{~S}\right)$ has

Corresponding author: William Martin (w.martin@uni-duesseldorf.de).

Available online 10 June 2004 been suggested [4]. Proponents on both sides have recently delivered hefty criticisms of the other $[5,6]$ without a compromise in sight.

\section{Concentrations and compartments}

Notwithstanding the continuing debate, there are other issues to be resolved with regard to the question of how life emerged. One of them is the 'concentration' problem pointed out by De Duve [7]: that is, how to attain sufficient concentrations of any mixture of organic compounds such that anything vaguely similar to a self-replicating system, for example in an RNA world, could arise on the early Earth. This is a stumbling block in both theories.

An organic soup dissolved in an ocean's worth of water would be simply too dilute to enable monomeric precursors to meet and to polymerise for self-replication [7]. Monomer concentrations are also a problem for the surface metabolism model, because once molecules have reacted on a surface they diffuse into the ocean, bringing us back to organic soup. The surface metabolism model suggests that the reaction products would be retained on a twodimensional surface until fully fledged cells emerged, but this would rapidly lead to blocking of the catalyst, bringing the reaction to an end. At the origin of biochemistry there must have been a concentrating mechanism, but of what kind?

Another related problem is the transition from disorganized solutions of organic molecules to free-living cells, which are always surrounded by a biological membrane and are always dependent on reductionoxidation (redox) reactions involving an electron donor and electron acceptor. The notion that lipid droplets came to encase self-replicating systems in solution ('coacervates') is inherent to both theories, but coacervates are not without their problems either, because it is not obvious how a cytosol could evolve with all of its enzymes and metabolites plus an underlying genome in free solution, without the pre-existence of (necessarily inorganic) compartments.

A solution to both problems (concentrations and compartmentation) can be found in the suggestion that life emerged in three-dimensional (3D) compartments consisting of $\mathrm{FeS}$ formed at the bottom of the ocean during the Hadean period (before $3.8 \times 10^{9}$ years [Gyr] ago) through the inflation of $\mathrm{FeS}$ precipitates by hydrothermal fluid $[8,9]$. Such naturally forming $3 \mathrm{D} \mathrm{FeS} \mathrm{compartments,}$ analogues of which have been reported from natural 
hydrothermal systems [10] (Figure 1), could have retained and ordered organic molecules produced by prebiotic reactions, rather than releasing them to dilution in the primordial ocean as in the organic soup or surface metabolism theories. By allowing sufficient concentrations of reactants to be generated and to accumulate, the hydrothermal reactor would permit the building blocks of life (bases, amino acids and sugars) to accumulate through continuous supply at their site of synthesis up to concentrations sufficient to support the origin of early selfreplicating systems until genuine, genetically encoded biological compartments - namely, membranes and cell walls - arose [11].

A continuous supply of monomeric components for life's polymeric constituents (nucleic acids and proteins) is essential because, for any system to replicate at the origin of life, it must regularly double its total mass of organic material [12]. Ample concentrations of monomers must be therefore in continuous supply - a perhaps obvious, but in our view seemingly insurmountable, problem underlying the organic soup and surface metabolism theories.

The first biochemical pathway: a geochemical pathway The chemical reactions through which life arose from the elements must have been thermodynamically favourable [13]. So what are the first chemical reactions that might have fuelled the first organic chemical and subsequently

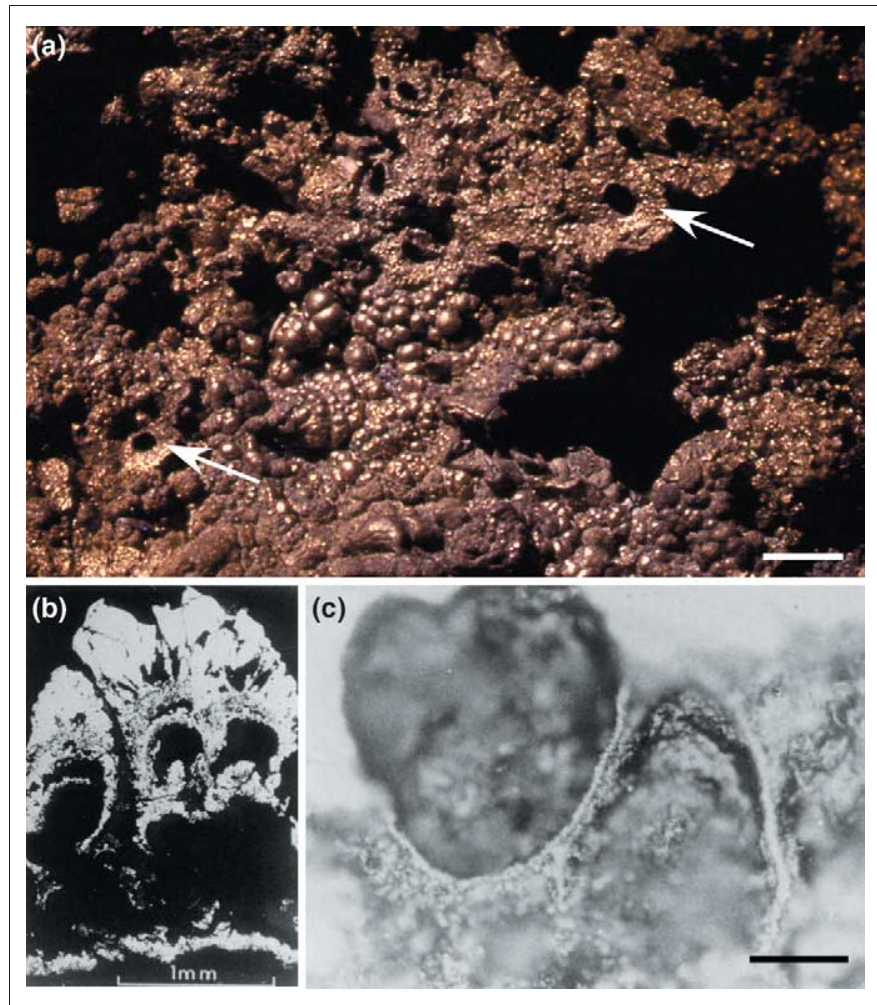

Figure 1. Naturally formed iron sulphide compartments. (a) Top view of a fossilized, 350-Myr-old iron-sulphur deposit from Tynagh, Ireland, that formed at a hydrothermal spring on the seafloor [10]. It comprises botryoids (the bubble-laden surface) and chimneys (arrows), through which the hydrothermal waters exhaled, leading to the iron sulphide deposit. Although ten times younger than the first life on Earth, this mineral sample illustrates the dynamics of deposition at seafloor hydrothermal mounds. The inset in Figure 3 might have looked similar, if viewed from the top. (b,c) Electron micrographs of a section of a Tynagh botryoid [10], showing the naturally formed, metal-sulphide-bounded compartments. Scale bar in (a) $=1 \mathrm{~cm}$; scale bar in (c) $=100 \mu \mathrm{m}$. first living system with energy and reduced carbon compounds? Traditional views point to glycolytic-like fermentations as the source of carbon and energy [3], and pyrite formation coupled to a reverse citric acid cycle (a pathway of $\mathrm{CO}_{2}$ fixation in some prokaryotes), which has construable similarities to imaginable inorganic reactions, has also been proposed [4,14].

As an alternative, Peretó et al. [15] have suggested that the linear acetyl-CoA or Wood-Ljungdahl pathway of $\mathrm{CO}_{2}$ fixation might be a better candidate than the above two for the first biochemical pathway (Box 1). The acetyl-CoA pathway is exergonic (i.e. it releases energy and thus will tend to occur), it is a linear pathway that does not require complicated biochemical intermediates to operate, and its biochemistry today involves organic reactions that are catalysed primarily by $\mathrm{FeS}$ and $(\mathrm{Fe}, \mathrm{Ni}) \mathrm{S}$ centres in proteins. These properties are highly compatible with the geochemically founded view that biochemistry arose within a hydrothermal mound made initially, among other things, of FeS and (Fe,Ni)S minerals [10,11].

In prokaryotes, the core enzyme in this pathway is carbon monoxide dehydrogenase (CODH) coupled with acetyl-CoA synthase (ACS). Its dual active-site reaction mechanism is thought to entail the reduction of $\mathrm{CO}_{2}$ to $\mathrm{CO}$ with the help of electrons (most commonly stemming from $\mathrm{H}_{2}$ ) at an $\mathrm{Fe}_{4} \mathrm{NiS}_{5}$ cluster called the 'C-cluster' [16], and the subsequent condensation at the 'A-cluster' of the carbonyl group (CO) with a methyl group (donated by a corrinoid FeS protein) to produce a metal-bound acetyl group, which is released from the enzyme via thiolysis, yielding a thioester product [16-20] (Figure 2). In the hydrogen-fermenting eubacterium Carboxydothermus hydrogenoformans, the acetyl-binding metal of ACS is

\section{Box 1. Thermodynamically better than a free lunch}

The overall reaction of the acetyl-CoA pathway, as it occurs in various autotrophic eubacteria and archaebacteria today, can be summarized as:

$4 \mathrm{H}_{2}+2 \mathrm{CO}_{2}+\mathrm{HSCoA} \rightarrow \mathrm{CH}_{3} \operatorname{CosCoA}+3 \mathrm{H}_{2} \mathrm{O}$

(Eqn 1)

with an estimated standard free energy $\left(\Delta G_{0}{ }^{\prime}\right)$ of $-59 \mathrm{~kJ} \mathrm{~mol}^{-1}[36]$, which is sufficient to drive ATP synthesis [37]. In a nutshell, the pathway reduces $\mathrm{CO}_{2}$ to form an energy-rich thioester in the presence of a thiol with the help of electrons supplied by $\mathrm{H}_{2}$, while releasing enough energy to make ATP via chemiosmosis in the process. The pathway converts inorganic carbon to organic carbon (a process that is essential for all life) and is thermodynamically favourable. Seen from a thermodynamic standpoint, organisms that use the acetyl-CoA pathway as their core energy-producing and $\mathrm{CO}_{2-}$ fixing route find themselves in "a geochemically provided benthic boondoggle" and "are given a free lunch that they are paid to eat" (Ref. [38], p. 73).

The acetate-producing reaction as it occurs in homoacetogenic prokaryotes is even more exergonic than the thioester-producing reaction [13]:

$4 \mathrm{H}_{2}+2 \mathrm{CO}_{2} \rightarrow \mathrm{CH}_{3} \mathrm{COOH}+2 \mathrm{H}_{2} \mathrm{O}$

(Eqn 2)

with thermodynamic values of $\Delta G_{\mathrm{r}}^{0}$ (standard molal Gibbs free energy) of $-172.32 \mathrm{~kJ} \mathrm{~mol}^{-1}$ at $2{ }^{\circ} \mathrm{C}$ and $-160.74 \mathrm{~kJ} \mathrm{~mol}^{-1}$ at $70{ }^{\circ} \mathrm{C}$ [39]. Although highly exergonic, the reaction does not take place in the absence of catalysis, which is provided today by metal-sulphide containing enzymes, owing to the high activation energy of the $\mathrm{CO}_{2}$ reducing reaction [40]. Notably, the reaction is more exergonic at low temperatures than at high temperatures [39]. 


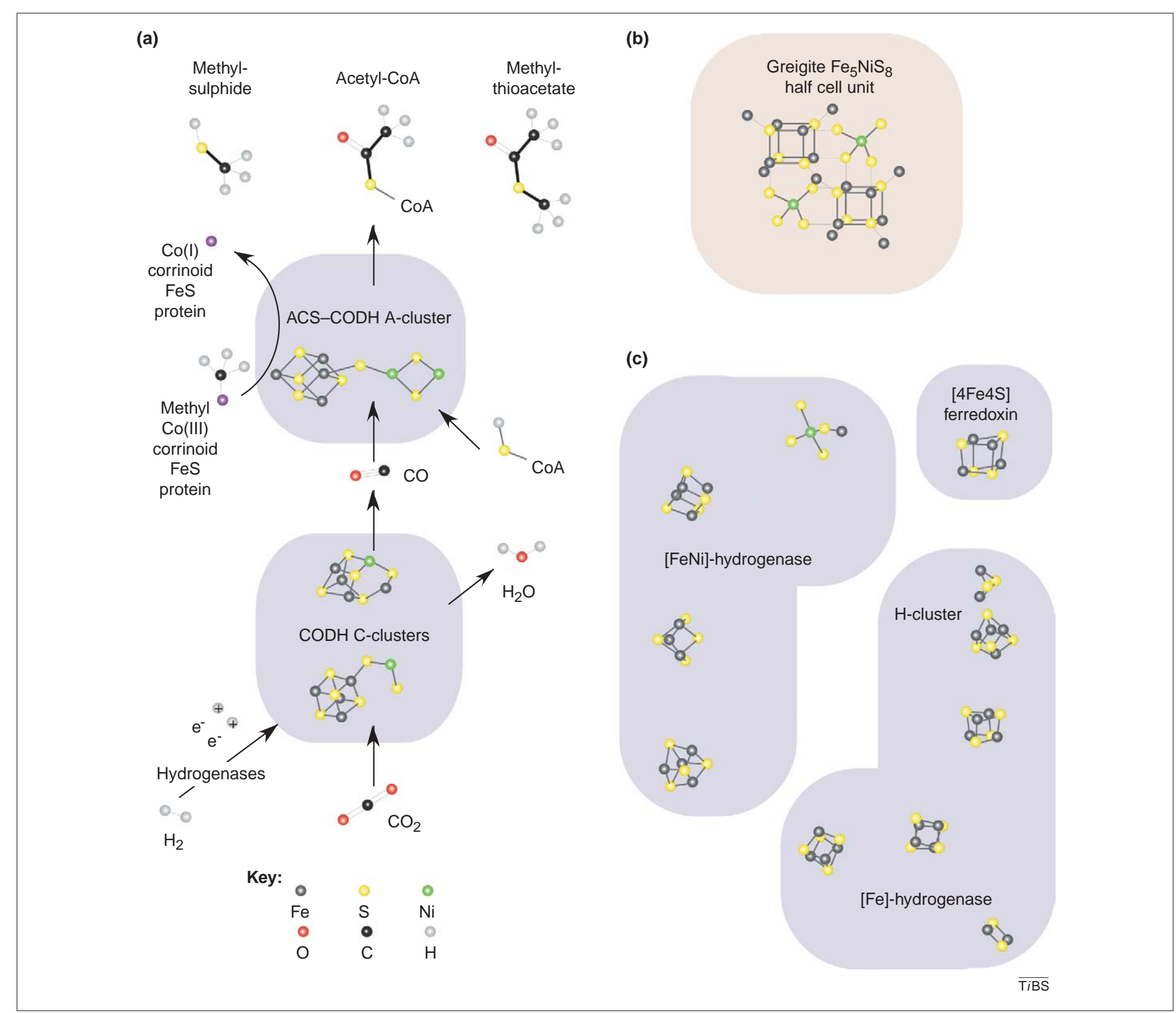

Figure 2. Structural similarity between ( $\mathrm{Fe}, \mathrm{Ni}) \mathrm{S}$ centres in enzymes and in minerals. (a) Cartoon of the carbon monoxide dehydrogenase (CODH) and acetyl-coenzyme- $\mathrm{A}$ (CoA) synthetase (ACS) reaction, based on structural data summarized in Refs [16-20,35]. The exact reaction mechanism for ACS has not been resolved: differing proposals have been put forth $[17,20]$ and differences have been also reported regarding the presence of copper, zinc and nickel at the active site of the $A$ cluster $[17,20,35]$; nickel has been found at the active site of the active enzyme [18]. Only selected metal sulphide centres of CODH and ACS are shown; the protein structure is represented by shading. The structures of methylsulphide, which has been synthesized from $\mathrm{H}_{2} \mathrm{~S}$ and $\mathrm{CO}_{2}$ via FeS catalysis [24], and methyl thioacetate (acetyl methylsulphide), which has been synthesized from $\mathrm{CO}$ and methylsulphide via NiS and FeS catalysis [25], are shown at the top for comparison. A reaction mechanism for the latter mineral-catalysed synthesis has been proposed [25]. (b) Structure of the $\mathrm{Fe}_{4}^{2.5+} \mathrm{S}_{4}$ 'cubane' unit in a half cell of the metastable mineral greigite $(\mathrm{SNiS})\left(\mathrm{Fe} \mathrm{S}_{4}\right)(\mathrm{SFeS})$; see Ref. [10] for further structural details and comparisons. (c) The $\mathrm{Fe}_{4} \mathrm{~S}_{4}$ 'thiocubane' units in other proteins that catalyse reactions of relevance to the acetyl-CoA pathway, namely, a ferredoxin [21], an [FeNi]-hydrogenase [22], and an iron-only [Fe]-hydrogenase [23], the proposed active site of which is called the 'H-cluster'.

nickel in a novel $\mathrm{Ni}-\mathrm{Ni}-[4 \mathrm{Fe} 4 \mathrm{~S}]$ cluster [18]. $\mathrm{CODH}$ and ACS can occur together as a single bifunctional enzyme (ACS-CODH) or as separate, monofunctional enzymes [19,20].

Acetyl-CoA, the product of the pathway, is a thioester. Thioesters are energy-rich and highly reactive compounds and, like ATP, they are an energy currency. De Duve [7] has made a strong case for an essential role of thioesters in the early phases of biochemical evolution. Glycolysis, the citric acid cycle, fatty acid biosynthesis, isoprenoid biosynthesis and reactions involving acetyl-CoA all use the reactivity of thioester bonds and their ability to store chemical energy [7]. Just as the hydrolysis of ATP releases energy, so does the hydrolysis of a thioester bond to the free thiol and an organic acid, which is acetate in the acetyl-CoA pathway (Box 1).

Long known among geochemists [8] but less well known among biochemists, the structure of the metal sulphur clusters in ACS-CODH are very similar to mineral forms of (Fe,Ni)S themselves (Figure 2). The structures of a C-cluster in CODH and of the A-cluster of ACS (Figure 2a) can be seen in a quarter cell of the metastable mineral greigite $(\mathrm{SNiS})\left(\mathrm{Fe}_{4} \mathrm{~S}_{4}\right)(\mathrm{SFeS})$ (Figure 2b). Furthermore, the cubic $\mathrm{Fe}_{4} \mathrm{~S}_{4}$ unit of greigite is found in the $\mathrm{Fe}_{4} \mathrm{~S}_{4}$ thiocubane units (called [4Fe4S] clusters in biochemistry) of other proteins of relevance to the acetyl-CoA pathway, 
namely, the electron carrier ferredoxin [21] and the electron-delivering hydrogenases [FeNi]-hydrogenase [22] and iron-only [Fe]-hydrogenase [23], the proposed active site of which is called the 'H-cluster'. In other words, the structure and atomic coordination of catalytically essential $(\mathrm{Fe}, \mathrm{Ni}) \mathrm{S}$ centres of $(\mathrm{Fe}, \mathrm{Ni}) \mathrm{S}$ proteins are not inventions of the biological world, rather they are mimics of minerals that are indisputably older and which themselves have catalytic activity in the absence of protein [24,25].

\section{The geochemical setting}

Is such an energy-releasing, $\mathrm{CO}_{2}$-fixing reaction plausible at the origin of biochemistry? For models of the origin of life at a hydrothermal vent, the answer is yes. For the setting, we suggest a mineral mound that channelled a highly reduced $\left(\mathrm{H}_{2}\right.$-containing) hydrothermal fluid to meet the $\mathrm{CO}_{2}$-rich ocean bottom water in a compartmentalized reactor consisting of freshly and continuously formed (Fe,Ni)S walls [10,11] (Figure 3). $\mathrm{H}_{2}$ is a significant constituent of hydrothermal fluid at deep-sea vents today [26], and at the origin of biochemistry some 4 billion years ago the concentration of $\mathrm{H}_{2}$ in hydrothermal fluid that vented into the Hadean ocean would have been even higher [10]. Furthermore, the Hadean ocean had higher concentrations of $\mathrm{CO}_{2}$ than have today's oceans [27]. Thus, the two principal reactants in the hydrothermal reactor model, $\mathrm{H}_{2}$ and $\mathrm{CO}_{2}$, certainly would have met at the interface between hydrothermal fluid and Hadean ocean bottom water (Figure 3); however, they would have done so across a colloidal barrier comprising metal sulphides, most notably FeS and NiS and variants thereof (Figure 3).

The type of vent central to this model is not the familiar 'black smoker', because black smokers are much too hot $\left(350{ }^{\circ} \mathrm{C}\right)$ for biochemical-like reactions [10]. And where, one might ask, did the metal sulphide colloidal barrier and compartments come from? Hydrothermal fluid, from the Hadean period until today, contains substantial amounts of $\mathrm{H}_{2} \mathrm{~S}$ (as $\mathrm{HS}^{-}$), which immediately precipitates as extremely insoluble metal sulphides when it comes into contact with dissolved metal ions such as $\mathrm{Fe}^{2+}$ (and $\mathrm{Ni}^{2+}$ ), which were present in abundance in the Hadean ocean [10]. Similarly formed metal sulphide precipitates can be seen in Figure 1. Today's oceans contain almost no $\mathrm{Fe}^{2+}$ but particulate $\mathrm{Fe}^{3+}$ instead, because the Earth is far more oxidized today than it was $4 \mathrm{Gyr}$ ago, owing to oxygenic photosynthesis. But $\mathrm{Fe}^{2+}$ was clearly the predominant form 4 Gyr ago [10].

The significance of metal sulphides in the hydrothermal reactor model is their catalytic activity in $\mathrm{CO}_{2}$ - and $\mathrm{CO}$ reducing reactions, both as metal sulphur clusters in proteins [16,28,29] (Figure 2) and as the free minerals themselves $[24,25]$. The significance of the $3 \mathrm{D}$ compartments comprising the reactor (Figures 1 and 3), which form a barrier to diffusion into the ocean, is their retention of just-synthesized organic molecules. Because of the various oxidation states of metals and sulphur, and because the relative stoichiometry of these elements can vary locally, natural ( $\mathrm{Fe}, \mathrm{Ni}) \mathrm{S}$ precipitates are typically mixtures of different minerals, among them $\mathrm{Fe}_{5} \mathrm{NiS}_{8}$, which is the mineral greigite.

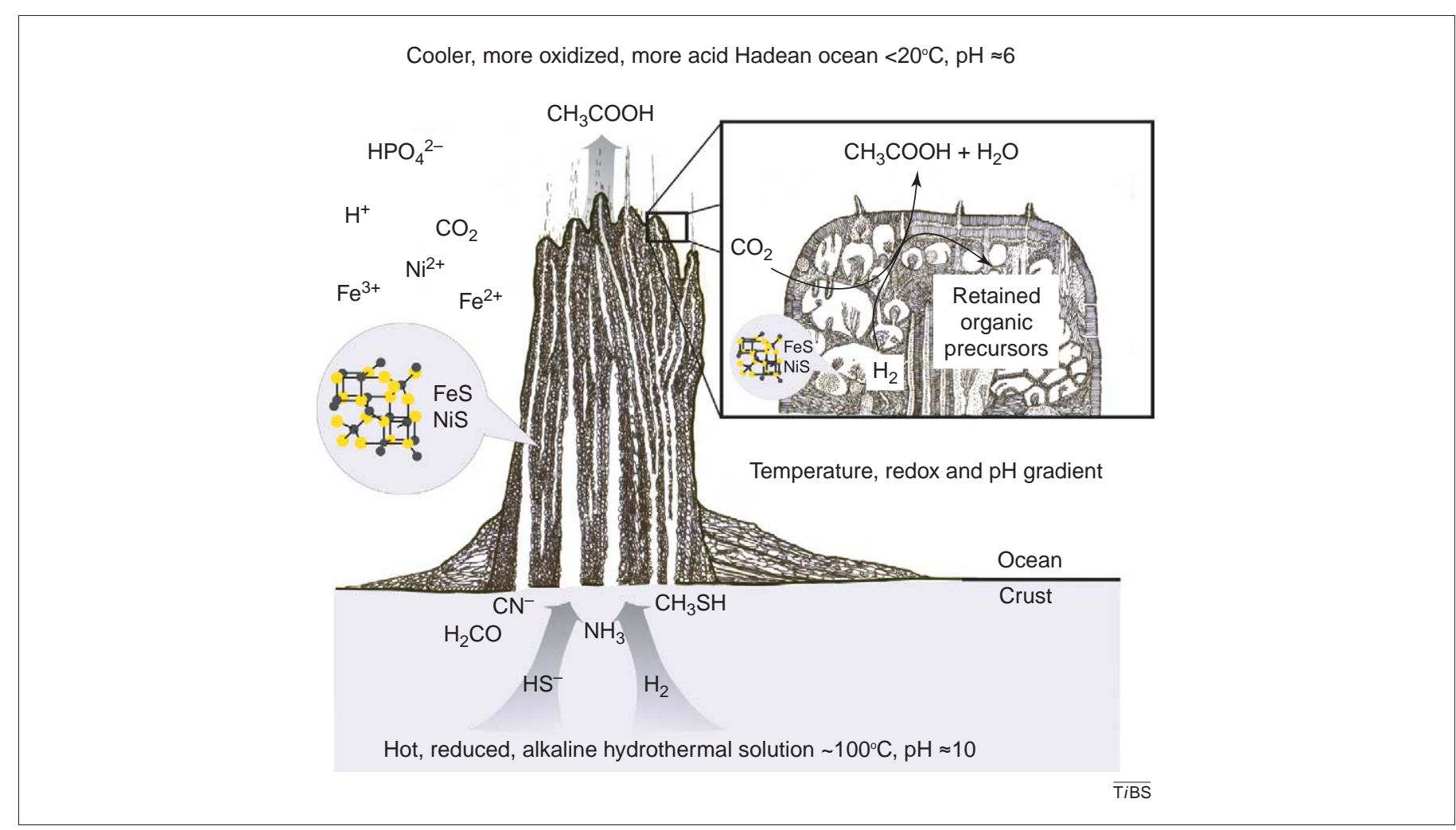

Figure 3. The kind of natural hydrothermal reactor developed at an alkaline submarine spring, proposed here to be the geological hatchery of life. Gradients in temperature $\left(110\right.$ to $\left.20^{\circ} \mathrm{C}\right), \mathrm{pH}(10$ to 6$)$ and redox $(-600 \mathrm{mV}$ to $+100 \mathrm{mV}$ ) are steepest at the mound's exterior. The mound comprises carbonates, clays, iron oxyhydroxides and sulphides. lonized and polar organic molecules are synthesized, concentrated, and ordered in the reactor [10,11]. Waste heat, water, unionized and nonpolar organic products, and much of the acetate are exhaled through self-forming chimneys. Inset shows an enlargement of one of the vents. 
Could such mineral clusters themselves have catalysed a primitive acetyl-CoA pathway [30,31]? Could a hydrothermal mound catalyse the production of acetate purely by inorganic means, thereby releasing energy for further chemical work? Experimental evidence supports this idea. The laboratory synthesis of methylsulphide $\left(\mathrm{CH}_{3} \mathrm{SH}\right)$ from $\mathrm{H}_{2} \mathrm{~S}$ and $\mathrm{CO}_{2}$ using only $\mathrm{FeS}$ as the catalyst has been shown [24]. Both the thioester acetyl methylsulphide $\left(\mathrm{CH}_{3-}\right.$ $\left.\mathrm{COSCH}_{3}\right)$ and its hydrolysed product, acetate $\left(\mathrm{CH}_{3} \mathrm{COO}^{-}\right)$, can be produced from $\mathrm{CO}$ and $\mathrm{CH}_{3} \mathrm{SH}$ by using only $\mathrm{FeS}$ and NiS as catalysts [25]. Similar work, albeit at high temperatures, has led to the synthesis of pyruvate [32], and (Fe,Ni)S can catalyse the synthesis of peptide bonds in the presence of $\mathrm{CO}$ [33]. In the hydrothermal reactor, therefore, we propose that such reactions are plausible.

\section{The acetyl-CoA pathway: simplicity}

The acetyl-CoA pathway as an initial biochemical route is also attractive because it does not require pre-existing organic 'primers', such as intermediates of the citric acid cycle, to operate. Wächtershäuser $[4,14]$ has suggested that electron transfer from $\mathrm{H}_{2} \mathrm{~S}$ to $\mathrm{FeS}$, which produces pyrite $\left(\mathrm{FeS}_{2}\right)$, would release energy that could be harnessed for primordial metabolism and $\mathrm{CO}_{2}$ fixation via the reverse citric acid cycle. It has also been suggested that Fe(III) would have been a suitable initial electron acceptor fuelling a reverse citric acid cycle [10]. In the acetyl-CoA pathway, however, $\mathrm{CO}_{2}$ is the electron acceptor, $\mathrm{H}_{2}$ is the donor, a $\mathrm{C} 2$ thioester is the product and the most complex organic intermediate is a methyl group. Because the thioesters are readily hydrolysed, the hydrothermal reactor would produce mainly acetate as waste (Box 1).

At the very earliest phases of biochemical evolution that we are considering here, there were no ATPases as we know them today to harness chemiosmotic potential, even though, in terms of the reactor model, there was natural chemiosmotic potential available at the hydrothermal mound by virtue of the alkalinity of hydrothermal fluid $(\mathrm{pH} \approx 9-10$ ) versus the acidity of the Hadean ocean ( $\mathrm{pH} \approx 5-6$ ), a difference of roughly four $\mathrm{pH}$ units [21]. But chemical energy from acetate production could nonetheless have been harnessed, provided that organic thiols were available in the reactor, which is extremely likely, for example, in the form of methylsulphide [24]. The thermodynamically favourable production of thioesters as highly reactive, energy-rich intermediates would fit very well with De Duve's [7] suggestions that thioesters were central to early biochemistry, but would exclude neither a role for pyrophosphates as early energy stores [34] nor a role for additional redox potential stemming from photolytically generated marine Fe(III) [21].

If a primitive analogue of the acetyl-CoA pathway, catalysed by metal sulphide centres as it is today in ACS$\mathrm{CODH}$, was involved, then thioesters would have been produced to undergo additional organic reactions. This analogue could have incorporated sulphur (and eventually, far down the line, organically housed metal sulphides and metal sulphide clusters in proteins) into a reactive byproduct, or precipitate, as a side activity of the main reaction. If we assume that ammonia was available in the hydrothermal fluid as the product of $\mathrm{N}_{2}$ reduction at high temperature and pressure deep in the crust [13], plus a bit of phosphate derived from the ocean, then with a large and continuous flux through this exergonic pathway, enough organic 'leftovers' could accumulate to start about the business of progressing from inorganic chemistry to the chemistry of life. The result would be a hydrothermal mound that produces acetate from $\mathrm{H}_{2}$ and $\mathrm{CO}_{2}$ with organic chemistry arising as a by-product.

Although it is still a long path from metal-sulphidecatalysed organic chemistry to fully fledged, free-living cells [11], one has to start somewhere: a hydrothermal reactor would contain, stably over geological time, a good set of continuously produced ingredients.

\section{Concluding remarks}

Did early biochemistry get started in catalytic metal sulphide compartments that arose at a hydrothermal mound in the Hadean ocean? Given the concentration problems associated with organic soup (too dilute from the start) and surface metabolism (the reaction in two dimensions blocks the catalyst or the products diffuse into the ocean to become dilute organic soup), perhaps we should be asking could it have happened any other way? For anything like a cell ever to emerge, the building blocks of biochemistry would have to have a continuous source of reduced carbon and energy and would have to remain concentrated at their site of sustained synthesis over extended times. Naturally forming compartments in FeS precipitates at a hydrothermal mound would solve the concentration problem neatly $[10,11]$.

The walls of such a structure would have been made of the minerals that, as metal and metal sulphide centres, catalyse the reduction of $\mathrm{CO}_{2}$ from $\mathrm{H}_{2}$ in the acetyl-CoA pathway [16-20], making it both a reasonable candidate for the first $\mathrm{CO}_{2}$-reducing pathway [15] and a rich source of thioesters - highly reactive central intermediates of biochemistry in all cells. Given that $\mathrm{FeS}$ and NiS can catalyse synthesis of methanethiol from $\mathrm{CO}_{2}$ and $\mathrm{H}_{2} \mathrm{~S}$ [24] and the synthesis of the thioester acetyl methylsulphide from $\mathrm{CO}$ and $\mathrm{CH}_{3} \mathrm{SH}$ in the laboratory [25], all of the constituents for a primordial role of the acetyl-CoA pathway seem to be in place. What is missing, however, is the synthesis of a thioester, such as acetyl methylsulphide, directly from $\mathrm{CO}_{2}$ and $\mathrm{H}_{2}$ in the presence of metal sulphides. A pathway that operates with two enzymes (ACS and $\mathrm{CODH}$ ) or one bifunctional one $(\mathrm{ACS}-\mathrm{CODH})$ is a good place from which to start from the standpoint of simplicity.

The argument has been made that the first cells produced acetate as a waste product, like many primitive anaerobes do today [15]. Given the structural (and catalytic) similarity between the minerals themselves and the catalytic centres of the enzymes in the acetyl-CoA pathway, an attractive idea is that the first cells simply conserved a thermodynamically favourable reaction that got started in a stable geochemical reactor with catalytic walls and a strong, sustained redox potential: in other words, in an acetate-producing hydrothermal mound.

\section{References}

1 Bernal, J.D. (1960) The problem of stages in biopoesis. In Aspects of the Origin of Life (Florkin, M., ed.), pp. 30-45, Pergamon Press 
2 Miller, S.M. and Schlesinger, G. (1983) Prebiotic synthesis in atmospheres containing $\mathrm{CH}_{4}, \mathrm{CO}$, and $\mathrm{CO}_{2}$. J. Mol. Evol. 19, 376-382

3 Lazcano, A. and Miller, S.L. (1999) On the origin of metabolic pathways. J. Mol. Evol. 49, 424-431

4 Wächtershäuser, G. (1988) Pyrite formation, the first energy source for life: a hypothesis. Syst. Appl. Microbiol. 10, 207-210

5 Bada, J.L. and Lazcano, A. (2002) Some like it hot, but not the first biomolecules. Science 296, 1982-1983

6 Borgeson, W. et al. (2002) Discussing the origin of life. Science 298, $747-749$

7 De Duve, C. (1991) Blueprint for a Cell: The Nature and Origin of Life, Neil Patterson Publishers

8 Russell, M.J. et al. (1994) A hydrothermally precipitated catalytic iron sulphide membrane as a first step toward life. J. Mol. Evol. 39, 231-243

9 Russell, M.J. et al. (2003) On the dissipation of thermal and chemical energies on the early Earth: the onsets of hydrothermal convection, chemiosmosis, genetically regulated metabolism and oxygenic photosynthesis. In Natural and Laboratory-Simulated Thermal Geochemical Processes (Ikan, R., ed.), pp. 325-388, Kluwer Academic Publishers

10 Russell, M.J. and Hall, A.J. (1997) The emergence of life from iron monosulphide bubbles at a submarine hydrothermal redox and $\mathrm{pH}$ front. J. Geol. Soc. (London) 154, 377-402

11 Martin, W. and Russell, M.J. (2003) On the origin of cells: an hypothesis for the evolutionary transitions from abiotic geochemistry to chemoautotrophic prokaryotes, and from prokaryotes to nucleated cells. Philos. Trans. R. Soc. London Ser. B 358, 27-85

12 Poole, A.M. et al. (1998) The path from the RNAworld. J. Mol. Evol. 46, $1-17$

13 Shock, E.L. (1992) Chemical environments of submarine hydrothermal systems. Orig. Life Evol. Biosph. 22, 67-107

14 Wächtershäuser, G. (1990) Evolution of the first metabolic cycles. Proc. Natl. Acad. Sci. U. S. A. 87, 200-204

15 Peretó, J.G. et al. (1999) Comparative biochemistry of $\mathrm{CO}_{2}$ fixation and the evolution of autotrophy. Int. Microbiol. 2, 3-10

16 Dobbeck, H. et al. (2001) Crystal structure of a carbon monoxide dehydrogenase reveals a [Ni-4Fe-5S] cluster. Science 293, 1281-1285

17 Doukov, T.I. et al. (2002) A Ni-Fe-Cu center in a bifunctional carbon monoxide dehydrogenase/acetyl-CoA synthase. Science 298, 567-572

18 Svetlitchnyi, V. et al. (2004) A functional Ni-Ni-[4Fe4S] cluster in the monomeric acetyl-CoA synthase from Carboxydothermus hydrogenoformans. Proc. Natl. Acad. Sci. U. S. A. 101, 446-451

19 Ragsdale, S.W. and Kumar, M. (1996) Nickel-containing carbon monoxide dehydrogenase/acetyl-CoA synthase. Chem. Rev. 96, 2515-2539

20 Lindahl, P.A. (2002) The Ni-containing carbon monoxide dehydrogenase family: Light at the end of the tunnel? Biochemistry 41, 2097-2105

21 Russell, M.J. and Hall, A.J. (2002) From geochemistry to biochemistry: chemiosmotic coupling and transition element clusters in the onset of life and photosynthesis. Geochem. News 113, 6-12

22 Volbeda, A. and Fontecilla-Camps, J.C. (2003) The active site and catalytic mechanism of NiFe hydrogenases. Dalton Trans. 1, 4030-4038
23 Nicolet, Y. et al. (2000) A novel FeS cluster in Fe-only hydrogenases. Trends Biochem. Sci. 25, 138-143

24 Heinen, W. and Lauwers, A.M. (1996) Organic sulfur compounds resulting from the interaction of iron sulfide, hydrogen sulfide and carbon dioxide in an anaerobic aqueous environment. Orig. Life Evol. Biosph. 26, 131-150

25 Huber, C. and Wächtershäuser, G. (1997) Activated acetic acid by carbon fixation on $(\mathrm{Fe}, \mathrm{Ni}) \mathrm{S}$ under primordial conditions. Science 276, 245-247

26 Kelley, D.S. et al. (2001) An off-axis hydrothermal vent field near the Mid-Atlantic Ridge at $30^{\circ} \mathrm{N}$. Nature $412,145-149$

27 Nisbet, E.G. and Sleep, N.H. (2001) The habitat and nature of early life. Nature 409, 1083-1091

28 Vaughan, D.J. and Craig, J.R. (1978) Mineral Chemistry of Natural Sulfides, p. 493, Cambridge University Press

29 Drennan, C.L. et al. (2001) Life on carbon monoxide: X-ray structure of Rhodospirillium rubrum Ni-Fe-S carbon monoxide dehydrogenase. Proc. Natl. Acad. Sci. U. S. A. 98, 11973-11978

30 Russell, M.J. et al. (1998) The emergence of life from FeS bubbles at alkaline hot springs in an acid ocean. In Thermophiles: The Keys to Molecular Evolution and the Origin of Life (Wiegel, J. and Adams, M.W.W., eds), pp. 77-125, Taylor and Francis

31 Milner-White, J. and Russell, M.J. Nests as sites for phosphates and iron-sulfur thiolates in the first membranes: 3 to 6 residue anionbinding motifs. Origins Life Evol. Bios. (in press)

32 Cody, G.D. et al. (2000) Primordial carbonylated iron-sulfur compounds and the synthesis of pyruvate. Science 289, 1337-1340

33 Huber, C. et al. (2003) A possible primordial peptide cycle. Science 301, 938-940

34 Baltscheffsky, M. et al. (1999) $\mathrm{H}^{+}$-PPases: a tightly membrane-bound family. FEBS Lett. 457, 527-533

35 Darnault, C. et al. (2003) Ni-Zn- $\left[\mathrm{Fe}_{4}-\mathrm{S}_{4}\right]$ and Ni-Ni-[ $\left.\mathrm{Fe}_{4}-\mathrm{S}_{4}\right]$ clusters in closed and open $\alpha$-subunits of acetyl-CoA synthase/carbon monoxide dehydrogenase. Nat. Struct. Biol. 10, 271-279

36 Fuchs, G. (1994) Variations of the acetyl-CoA pathway in diversely related microorganisms that are not acetogens. In Acetogenesis (Drake, H.L., ed.), pp. 506-538, Chapman and Hall

37 Thauer, R.K. et al. (1977) Energy conservation in chemotrophic anaerobic bacteria. Bacteriol. Rev. 41, 100-180

38 Shock, E.L. et al. (1998) The emergence of metabolism from within hydrothermal systems. In Thermophiles: The Keys to Molecular Evolution and the Origin of Life (Wiegel, J. and Adams, M.W.W., eds), pp. 59-76, Taylor and Francis

39 Amend, J.P. and Shock, E.L. (2001) Energetics of overall metabolic reactions of thermophilic and hyperthermophilic Archaea and Bacteria. FEMS Microbiol. Rev. 25, 175-243

40 Keene, F.R. (1993) Thermodynamic, kinetic, and product considerations in carbon dioxide reactivity. In Electrochemical and Electrocatalytic Reactions of Carbon Dioxide (Sullivan, B.P. et al., eds), pp. 118-144, Elsevier

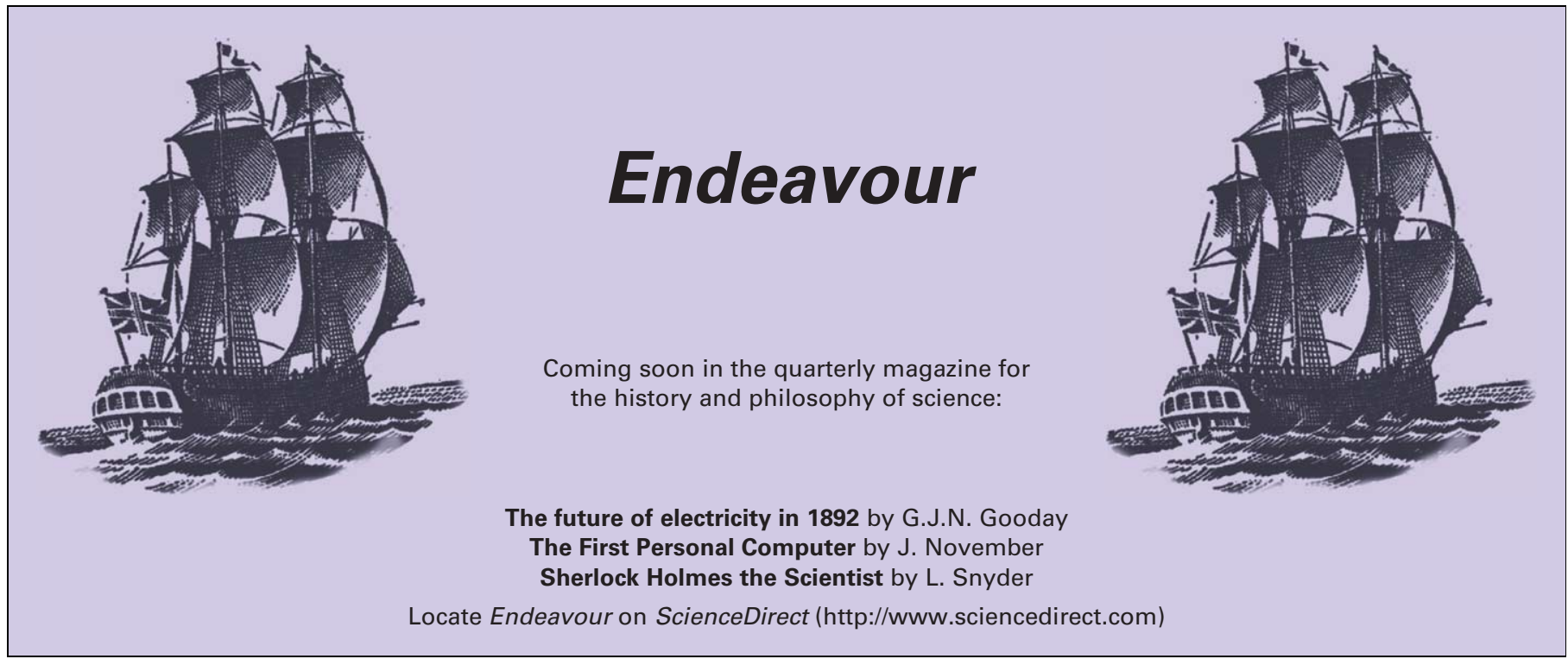

